\title{
Efeito de diferentes proporções de moinha de café na composição de substratos alternativos para produção de mudas de pepino
}

\author{
Effect of different proportions of coffee chaff on the composition of alternative substrates for \\ producing cucumber seedlings
}

\section{Karoline Matiello Almeida ${ }^{1 *}$, Paola Alfonsa Vieira Lo Monaco², Ismail Ramalho Haddade ${ }^{2}$, Marcelo Rodrigo Krause ${ }^{1}$, Louise Pinto Guisolfi ${ }^{1}$ \& Lorena Aparecida Merlo Meneghelli'}

\author{
${ }^{1}$ Universidade Federal de Viçosa, Viçosa, MG, Brasil. *Autor para correspondência: karolinematiello@hotmail.com. \\ ${ }^{2}$ Instituto Federal do Espírito Santo, Santa Teresa, ES, Brasil.
}

Submissão: 22/03/2017 | Aceite: 13/06/2018

\begin{abstract}
RESUMO
Um dos principais fatores relacionados à qualidade das mudas de olerícolas é o tipo de substrato utilizado. Avaliaram-se as variáveis de crescimento de mudas de pepino produzidas em substratos com níveis crescentes de resíduo da secagem dos grãos de café (moinha) em substituição ao uso exclusivo do substrato comercial. O experimento foi realizado no delineamento inteiramente casualizado, com seis tratamentos e dez repetições, sendo: T1: Substrato comercial (SC); T2: 0\% de moinha (MO)+ 40\% de casca de arroz carbonizada (CAC) $+15 \%$ de fibra de coco (FC) $+5 \%$ de casca de ovo (CO) $+40 \%$ de SC; T3: $10 \%$ de $\mathrm{MO}+40 \%$ de CAC $+15 \%$ de $\mathrm{FC}+5 \%$ de $\mathrm{CO}+30 \%$ de SC; T $4: 20 \%$ de $\mathrm{MO}+40 \%$ de CAC+ $15 \%$ de $\mathrm{FC}+5 \%$ de $\mathrm{CO}+20 \%$ de SC $; \mathrm{T} 5: 30 \%$ de $\mathrm{MO}+40 \%$ de $\mathrm{CAC}+15 \%$ de $\mathrm{FC}+5 \%$ de $\mathrm{CO}+10 \%$ de SC; T6: $40 \%$ de $\mathrm{MO}+40 \%$ de CAC $+15 \%$ de FC + 5\% CO + 0\% SC. Avaliou-se condutividade elétrica dos substratos, matéria seca do sistema radicular e parte aérea, altura de plântula, diâmetro de caule e número de folhas. Proporções crescentes de moinha acarretam no aumento da condutividade elétrica do substrato. Proporções em torno de 15 a $20 \%$ de moinha na composição do substrato apresentam os maiores valores de matéria seca da parte aérea, de raiz e diâmetro do caule. Proporções de até $30 \%$ de moinha em substrato composto por $40 \%$ de CAC, $15 \%$ de FC, $5 \%$ de CO e $10 \%$ de SC, também podem ser utilizados sem que haja prejuízo nas variáveis de crescimento de mudas de pepino.
\end{abstract}

PALAVRAS-CHAVE: resíduos agrícolas, substrato, Cucumis sativus.

\begin{abstract}
One of the main factors related to the quality of edible vegetable seedlings is the type of substrate used. The growth variables of cucumber seedlings grown on alternative substrates to the commercial substrate, having increasing levels of coffee drying residues (chaff). The experiment was conducted under a completely randomized design with six treatments and ten replications, where: T1: commercial substrate (CS); T2: $0 \%$ chaff $(\mathrm{CH})+40 \%$ carbonized rice husk $(\mathrm{CRH})+15 \%$ coconut fiber $(\mathrm{CF})+5 \%$ eggshell $(\mathrm{ES})$ $+40 \% \mathrm{CS}$; T3: $10 \% \mathrm{CH}+40 \% \mathrm{CRH}+15 \% \mathrm{CF}+5 \% \mathrm{ES}+30 \% \mathrm{CS} ; \mathrm{T} 4: 20 \% \mathrm{CH}+40 \% \mathrm{CRH}+15 \% \mathrm{CF}+$ $5 \% \mathrm{ES}+20 \% \mathrm{CS} ; \mathrm{T} 5: 30 \% \mathrm{CH}+40 \% \mathrm{CRH}+15 \% \mathrm{CF}+5 \% \mathrm{ES}+10 \% \mathrm{CS} ; \mathrm{T} 6: 40 \% \mathrm{CH}+40 \% \mathrm{CRH}+$ $15 \% \mathrm{CF}+5 \% \mathrm{ES}+0 \% \mathrm{CS}$. The variables evaluated were electrical conductivity of substrates, dry mass of the root system and the aerial part, seedling height, stem diameter and number of leaves. Increasing proportions of chaff also increase the electrical conductivity of the substrate. Proportions around 15 to $20 \%$ of chaff in the composition of the substrate present the highest values of stem diameter, dry mass of the root system and of the aerial part. Proportions up to $30 \%$ of the substrate constituted by $40 \%$ rice husk, $15 \%$ coconut fiber, $5 \%$ egg husk and $10 \%$ commercial substrate can also be used without loss in the growth variables of cucumber seedlings.
\end{abstract}

KEYWORDS: agricultural residues, substrate, Cucumis sativus.

\section{INTRODUÇÃO}

Nos últimos anos, o cultivo do pepino (Cucumis sativus) tem se tornado bastante atrativo aos produtores de hortaliças de todo o país em razão de seu rápido retorno do capital.

Dentro da cadeia produtiva de hortaliças, um fator decisivo para a obtenção de mudas com qualidade 
é o tipo de substrato utilizado. Na agricultura convencional, utilizam-se comumente os substratos comerciais à base de fibras vegetais e vermiculita expandida, sendo utilizados como fonte de nutrição para as mudas (ARAÚJO NETO et al. 2009).

De modo a reduzir os custos com esses substratos comerciais, o aproveitamento de resíduos agrícolas disponíveis nas propriedades para produção de mudas, constitui-se numa fonte de nutrientes economicamente viável, por reduzir os custos decorrentes da aquisição de fertilizantes sintéticos (SILVA et al. 2009). Além disso, é uma forma de minimizar o impacto ambiental causado pelo descarte de forma inadequada desses resíduos no ambiente.

Dentre alguns resíduos gerados em elevada quantidade no Estado do Espírito Santo, e com potencial para serem utilizados na composição de substratos alternativos para produção de mudas de pepino, destacam-se a fibra de coco, a casca de arroz carbonizada, a casca de ovo e o resíduo da secagem dos grãos de café, conhecido também por "moinha".

Em razão de alguns atributos tais como longa durabilidade, abundância da matéria prima renovável e o baixo custo da fibra de coco (CARRIJO et al. 2002), a boa drenagem e a baixa densidade proporcionadas pela casca de arroz carbonizada (CASTOLDI et al. 2014), a elevada quantidade de cálcio existente na casca do ovo (MEDEIROS \& ALVES 2014) e pelo potencial fertilizante, sobretudo do nitrogênio existente na moinha (MENEGHELLI et al. 2016), tais resíduos tornam-se interessantes na composição de um substrato alternativo ao comercial.

Apesar do potencial fertilizante da moinha, MENEGHELLI et al. (2016) constataram uma elevada condutividade elétrica neste resíduo, razão pela qual verificaram que concentrações maiores que $10 \%$ de moinha no substrato proporcionaram valores inferiores nas variáveis analisadas em mudas de café Conilon. Nesse sentido, diferentes concentrações de moinha na composição do substrato e em diferentes culturas devem ser pesquisadas, tal como em mudas de pepino, considerando a hipótese de que este resíduo é um importante componente no substrato, porém, numa proporção adequada que carece de experimentação.

Dessa maneira, acredita-se que a substituição parcial ou até mesmo total dos substratos comerciais pela combinação de diferentes resíduos agrícolas possa ser uma alternativa sustentável para a produção de mudas de pepino, sendo que todos eles apresentam características favoráveis à germinação e ao desenvolvimento das mudas. Além disso, ARAÚJO NETO et al. (2009) reforçam que é praticamente impossível encontrar um substrato com todas as características desejáveis, necessitando-se verificar experimentalmente, para cada espécie vegetal, qual o substrato ou a melhor mistura de substratos que permita obter mudas de qualidade.

Assim, objetivou-se avaliar as variáveis de crescimento de mudas de pepino produzidas em substratos alternativos com níveis crescentes de resíduo da secagem dos grãos de café (moinha) em substituição ao uso exclusivo do substrato comercial.

\section{MATERIAL E MÉTODOS}

O experimento foi implantado e conduzido no viveiro de produção de mudas do Instituto Federal do Espírito Santo - Campus Santa Teresa, no município de Santa Teresa, Espírito Santo $\left(18^{\circ} 48^{\prime} \mathrm{S} ; 40^{\circ} 40^{\prime} \mathrm{O} ; 145\right.$ $\mathrm{m}$ de altitude). O clima, segundo a classificação de Köppen, enquadra-se no tipo Cwa (subtropical de inverno seco), com temperatura média anual de $24,6{ }^{\circ} \mathrm{C}$ e precipitação média anual variando entre 700 a $1200 \mathrm{~mm}$. A temperatura e a umidade relativa do ar no período experimental variaram entre 19,9 a $38,2^{\circ} \mathrm{C}$ e 47,5 a $69,5 \%$, respectivamente. O viveiro onde foi desenvolvido o trabalho era coberto com tela de sombreamento, o que proporcionava a redução da radiação solar em $50 \%$.

Os resíduos utilizados no substrato alternativo para produção de mudas de pepino foram o resíduo proveniente da secagem dos grãos de café, denominado como "moinha", a casca de ovo, a fibra de coco e a casca de arroz carbonizada. A casca de ovo foi coletada em restaurantes da região e seca ao sol por três dias. Posteriormente, foi triturada em almofariz, até se obter um farelo na forma de pó. A casca de arroz carbonizada e a fibra de coco foram doadas pela Empresa Fibria, localizada em Aracruz, ES. Já a moinha foi coletada da propriedade "Sítio da Saudade", localizada próxima à área do experimento em Santa Teresa, ES. Antes de ser utilizada, a moinha foi peneirada em peneira granulométrica inox com malha de $4 \mathrm{~mm}$.

A caracterização química e físico-química dos resíduos utilizados na composição dos substratos para a produção de mudas de pepino foi realizada no Laboratório de Solos e Resíduos Sólidos do Departamento de Engenharia Agrícola da Universidade Federal de Viçosa. A análise físico-química consistiu na determinação da condutividade elétrica (CE), por meio de um condutivímetro de bancada. $A$ análise química consistiu na determinação do $\mathrm{pH}$, por meio de um peagâmetro de bancada, e na quantificação das concentrações de carbono orgânico facilmente oxidável ( $\mathrm{CO}_{\mathrm{fo}}$ ), carbono orgânico total (COT), nitrogênio total 
$(\mathrm{NT})$, fósforo $(\mathrm{P})$ e potássio $(\mathrm{K})$, seguindo-se metodologia descrita por MATOS (2015). Na Tabela 1 apresentam-se os atributos químicos e físico-químico (CE) da fibra de coco, da moinha, da casca de ovo e da casca de arroz carbonizada utilizadas no experimento.

Tabela 1. Atributos químicos e físico-químico (CE) da casca de ovo (CO), fibra de coco (FC), moinha (MO) e casca de arroz carbonizada (CAC) utilizadas no experimento. IFES, Campus Santa Teresa, 2017.

Table 1. Chemical and physical-chemical (EC) attributes of egg shell (ES), coconut fiber (CF), chaff (CH) and carbonized rice husk (CRH) were used in the experiment. IFES, Campus Santa Teresa, 2017.

\begin{tabular}{cccccccc}
\hline \multirow{2}{*}{ Resíduos } & \multirow{2}{*}{$\mathrm{pH}$} & $\begin{array}{c}\mathrm{CE} \\
\mathrm{dS} \mathrm{m}{ }^{-1}\end{array}$ & $\mathrm{CO}_{\text {fo }}$ & $\mathrm{CO}$ & $\mathrm{N}_{\mathrm{T}}$ & $\mathrm{P}$ & $\mathrm{K}$ \\
\hline $\mathrm{CO}$ & 9,37 & 0,37 & 2,8 & 3,6 & 0,87 & 0,084 & 0,06 \\
$\mathrm{FC}$ & 7,15 & 0,09 & 57,1 & 74,1 & 0,66 & 0,053 & 0,14 \\
MO & 5,60 & 6,49 & 45,3 & 58,9 & 3,7 & 0,14 & 0,71 \\
CAC & 5,9 & 1,15 & 31,5 & 40,9 & 0,593 & 0,0816 & 0,0329 \\
\hline
\end{tabular}

$\mathrm{p} \overline{\mathrm{H}}=$ potencial hidrogeniônico em água; $\mathrm{CE}=$ condutividade elétrica; $\mathrm{CO}_{\mathrm{to}}=$ carbono orgânico facilmente oxidável; $\mathrm{CO}_{\mathrm{t}^{-}}=$carbono orgânico total; $\mathrm{N}_{\mathrm{t}}=$ nitrogênio total; $\mathrm{P}=$ fósforo; $\mathrm{K}=$ potássio.

Assim, foram avaliados os seguintes tratamentos: T1: Substrato comercial (testemunha); T2: $0 \%$ de moinha $(\mathrm{MO})+40 \%$ de casca de arroz carbonizada (CAC) $+15 \%$ de fibra de coco $(F C)+5 \%$ de casca de ovo (CO) $+40 \%$ de substrato comercial (SC); T3: $10 \%$ de $\mathrm{MO}+40 \%$ de CAC $+15 \%$ de $\mathrm{FC}+5 \%$ de $\mathrm{CO}+$ $30 \%$ de SC; T4: $20 \%$ de $\mathrm{MO}+40 \%$ de CAC $+15 \%$ de $\mathrm{FC}+5 \%$ de $\mathrm{CO}+20 \%$ de SC; $5: 30 \%$ de $\mathrm{MO}+$ $40 \%$ de $\mathrm{CAC}+15 \%$ de $\mathrm{FC}+5 \%$ de $\mathrm{CO}+10 \%$ de SC; 6 : $40 \%$ de $\mathrm{MO}+40 \%$ de CAC $+15 \%$ de FC $+5 \%$ de $\mathrm{CO}+0 \%$ de SC.

O delineamento experimental adotado foi o inteiramente casualizado (DIC), com seis tratamentos e dez repetições. Cada unidade experimental consistiu de 20 mudas, considerando-se seis plantas úteis para cada unidade experimental.

$\mathrm{Na}$ Tabela 2, apresentam-se os atributos químicos do substrato comercial Bioplant ${ }^{\circledR}$, obtido por PAIXÃO et al. (2012).

Tabela 2. Análise química do substrato Bioplant ${ }^{\circledR}$. IFES, Campus Santa Teresa, 2017.

Table 2. Chemical analysis of the Bioplant ${ }^{\circledR}$ substrate. IFES, Campus Santa Teresa, 2017.

\begin{tabular}{|c|c|c|c|c|c|c|}
\hline \multirow[t]{2}{*}{$\mathrm{pH}^{1}$} & $\mathrm{~N}_{\mathrm{T}}$ & $\mathrm{P}$ & $\mathrm{K}$ & $\mathrm{Ca}$ & $\mathrm{CO}_{\mathrm{T}}$ & $\mathrm{MO}$ \\
\hline & \multicolumn{6}{|c|}{ 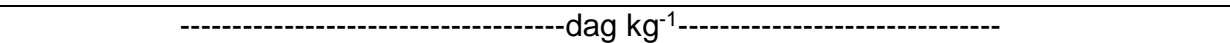 } \\
\hline 5,62 & 0,62 & 1,55 & 0,44 & 1,84 & 21,0 & 52,21 \\
\hline
\end{tabular}

${ }^{1} \mathrm{pH}$ em $\mathrm{CaCl}_{2}(\mathrm{CaCl} 2 \mathrm{pH})$

As sementes de pepino utilizadas foram do tipo "Caipira", sendo semeadas em bandejas de plástico com 200 células, colocando-se uma semente por célula.

Utilizou-se o sistema de produção de mudas em bandejas suspensas, alocadas em bancadas de alvenaria, irrigadas manualmente duas vezes ao dia, pela manhã e à tarde. Não foi realizada qualquer adubação com fertilizantes.

As avaliações ocorreram aos 21 dias após semeadura (DAS) consistindo-se na medição da altura de plântula e do diâmetro de caule, quantificação das massas secas da parte aérea e raiz da planta e contagem do número de folhas. Para a obtenção da altura da parte aérea foi utilizada uma régua milimetrada, medindo-se da base do caule até a gema apical que deu origem à última folha. $O$ diâmetro do caule foi obtido por meio de um paquímetro digital de precisão. A massa seca da parte aérea foi obtida através do corte das mudas próximas ao substrato. Para a obtenção das massas secas da parte aérea e da raiz, realizou-se o corte das mudas próximas ao substrato, lavando-se cuidadosamente as raízes em água corrente sobre peneira. Em seguida, a parte aérea e as raízes foram acondicionadas em sacos de papel e alocadas em estufa com circulação de ar forçado a $65{ }^{\circ} \mathrm{C}$ por 72 horas. Posteriormente, realizou-se a pesagem dos materiais em balança eletrônica de precisão de 0,01 g. Além das análises biométricas e gravimétricas, determinou-se, por meio de um condutivímetro, a condutividade elétrica dos substratos, seguindo-se metodologia proposta por MATOS (2015).

Todas as variáveis avaliadas foram submetidas aos testes de normalidade (Lilliefors), de aditividade (Tukey) e de homocedasticidade (Barttlet), estes, pressupostos para a validação de suas análises de variância. Aquelas que não atenderam aos requisitos foram transformadas, conforme critérios citados por 
GRAVINA et al. (2004), sendo novamente submetidas aos mesmos testes de validação. Para as variáveis que novamente não atenderam aos pressupostos, optou-se por sua avaliação por meio do teste não paramétrico de Kruskal-Wallis, contemplando-se a avaliação dos efeitos dos tratamentos por postos, ou escalas de ordenação.

Dada a diferença qualitativa entre o tratamento de substrato comercial (T1) e os demais (T2 a T6), efetuou-se o teste Dunnet comparando-se cada tratamento com o T1 (testemunha). Além destas, para o caso de efeitos significativos $(p<0,05)$ para as comparações entre os tratamentos T2, T3, T4, T5, T6 relacionados ao nível de moinha, adotaram-se seus ajustes em modelos de regressão pelo método dos polinômios ortogonais. Para todos os procedimentos foi adotado um " $a$ " igual a 0,05.

Todas as análises estatísticas foram realizadas por meio programa SAEG 9.1 - UFV (2007).

\section{RESULTADOS E DISCUSSÃO}

$\mathrm{Na}$ Figura 1 apresenta-se a condutividade elétrica nos diferentes substratos, comparando-se os postos médios de cada tratamento pelo teste não-paramétrico de Kruskal-Wallis, ao nível de $5 \%$ de probabilidade.

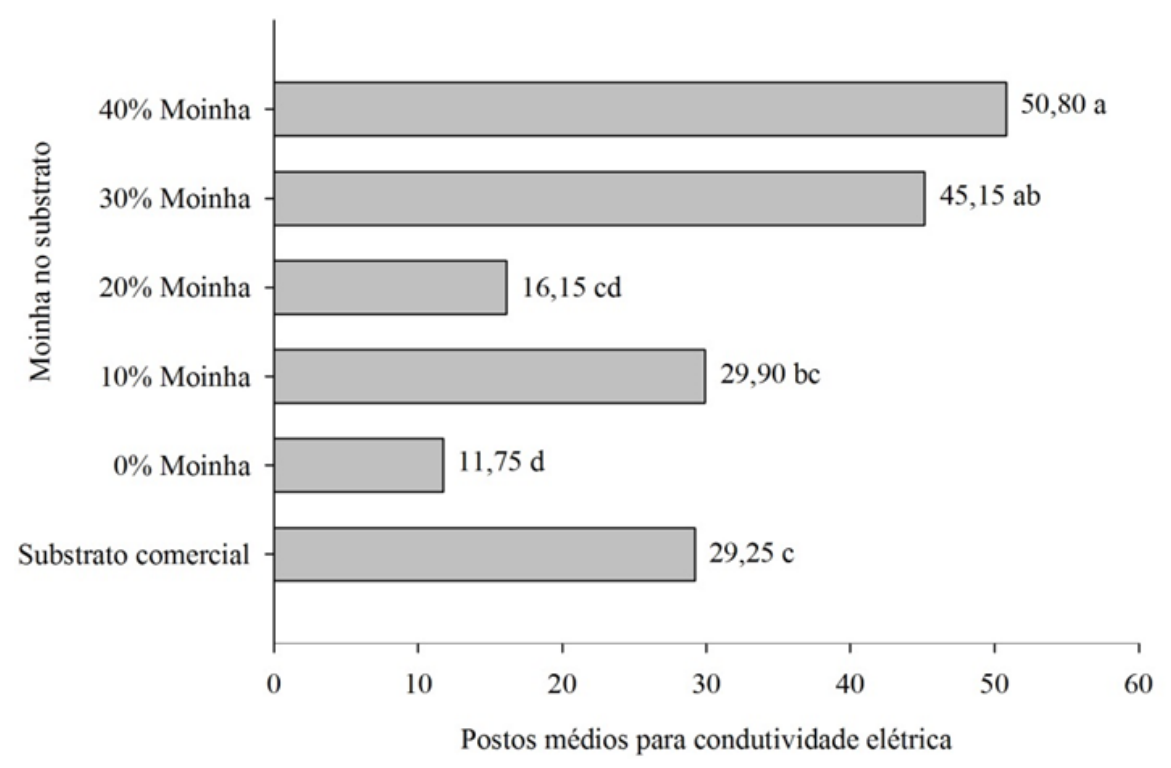

Figura 1. Comparações dos postos médios para a variável condutividade elétrica dos substratos por meio do teste não paramétrico de Kruskal-Wallis a $5 \%$ de probabilidade. IFES, Campus Santa Teresa, 2017.

Figure 1. Comparisons between average positions for the variable electrical conductivity of the substrates by means of the Kruska- Wallis non-parametric test at 5\% probability. IFES, Campus Santa Teresa, 2017.

De acordo com a Figura 1, verifica-se que o tratamento testemunha não diferiu dos tratamentos com 10 e $20 \%$ de moinha e estes foram inferiores aos demais tratamentos $(p<0,05)$, exceto para $o$ tratamento que não possui moinha, o qual apresentou o menor valor de condutividade elétrica. De um modo geral, o aumento da concentração de moinha no substrato proporcionou acréscimos nos valores de CE. Tal resultado já era esperado em razão da moinha ser um resíduo de elevada CE quando comparado com outros resíduos (Tabela 1).

A elevada salinidade acarreta num decréscimo do potencial osmótico no substrato, afetando negativamente a absorção de água pelas raízes. De acordo com RIBEIRO et al. (2001), a alta concentração de sais é um fator de estresse para as plantas, pois reduz o potencial osmótico e proporciona a ação dos íons sobre o protoplasma. A água é osmoticamente retida na solução salina, de forma que o aumento da concentração de sais a torna cada vez menos disponível para as plantas (RIBEIRO et al. 2001).

Mesmo assim, os substratos contendo níveis crescentes de moinha, misturados a outros resíduos, não proporcionaram valores que possam causar prejuízos ao desenvolvimento das mudas. CAVINS et al. (2000) classificam a CE em níveis: muito baixo $\left(0\right.$ a $\left.0,25 \mathrm{dS} \mathrm{m}^{-1}\right)$, baixo $\left(0,26\right.$ a $\left.0,75 \mathrm{dS} \mathrm{m}^{-1}\right)$, normal $(0,76$ a $\left.1,25 \mathrm{dS} \mathrm{m}^{-1}\right)$, alto $\left(1,26\right.$ a $\left.1,75 \mathrm{dS} \mathrm{m}^{-1}\right)$, muito alto $\left(1,76\right.$ a $2,25 \mathrm{dS} \mathrm{m}^{-1}$ ) e extremo (acima de 2,25 $\mathrm{dS} \mathrm{m}^{-1}$ ). Neste caso, o maior valor alcançado neste trabalho $\left(0,0508 \mathrm{dS} \mathrm{m}^{-1}\right)$, decorrente da maior concentração de 
moinha, encontra-se na faixa considerada muito baixa.

$\mathrm{Na}$ Tabela 3 são apresentados os valores médios de massa seca da parte aérea (MSPA), massa seca de raiz (MSR), diâmetro de caule (DC), altura de planta (AP) e número de folhas (NF) de mudas de pepino em função dos substratos utilizados com diferentes proporções de moinha, aos 21 DAS.

Tabela 3. Valores médios de massa seca da parte aérea (MSPA), massa seca de raiz (MSR), diâmetro de caule (DC), altura de planta (AP) e número de folhas (NF) de mudas de pepino em função dos substratos utilizados com diferentes proporções de moinha, aos 21 DAS. IFES, Campus Santa Teresa, 2017.

Table 3. Average dry mass of the aerial part (DMAP), root dry mass (RDM), stem diameter (SD), plant height (PH) and number of leaves (NL) of cucumber seedlings according to the substrates used with different proportions of chaff, at 21 DAS. IFES, Campus Santa Teresa, 2017.

\begin{tabular}{cccccc}
\hline Tratamento & $\begin{array}{c}\text { MSPA }^{1} \\
(\mathrm{mg})\end{array}$ & $\begin{array}{c}\text { MSR } \\
(\mathrm{mg})\end{array}$ & $\begin{array}{c}\text { DC } \\
(\mathrm{mm})\end{array}$ & $\begin{array}{c}\text { AP } \\
(\mathrm{cm})\end{array}$ & $\begin{array}{c}\mathrm{NF} \\
(\mathrm{un})\end{array}$ \\
\hline T1 & 56,17 & 14,17 & 1,83 & 7,71 & 3,08 \\
T2 & 60,83 & 16,83 & $2,19^{\star}$ & 9,51 & 3,07 \\
T3 & 57,33 & 14,50 & $2,53^{\star}$ & 8,96 & 3,13 \\
T4 & 67,50 & 16,00 & $2,74^{*}$ & 9,72 & 3,13 \\
T5 & 60,00 & 13,33 & $2,58^{*}$ & 8,24 & 3,10 \\
T6 & 48,33 & $9,33^{*}$ & $2,37^{\star}$ & 7,60 & 3,05 \\
\hline Valor de P & 0,0400 & 0,0395 & $3,64^{\star} 10^{-9}$ & $1,40^{\star} 10^{-5}$ & 0,73 \\
\hline
\end{tabular}

T1: Substrato comercial (testemunha); T2: $0 \%$ de moinha (MO) $+40 \%$ de casca de arroz carbonizada (CAC) $+15 \%$ de fibra de coco (FC) $+5 \%$ de casca de ovo (CO) $+40 \%$ de substrato comercial (SC); T3: $10 \%$ de $\mathrm{MO}+40 \%$ de $\mathrm{CAC}+15 \%$ de $\mathrm{FC}+5 \%$ de $\mathrm{CO}+30 \%$ de SC; T4: $20 \%$ de $\mathrm{MO}+40 \%$ de CAC $+15 \%$ de FC $+5 \%$ de CO $+20 \%$ de SC; T5: $30 \%$ de $\mathrm{MO}+40 \%$ de CAC $+15 \%$ de $\mathrm{FC}+5 \%$ de $\mathrm{CO}+10 \%$ de SC ; T6: $40 \%$ de $\mathrm{MO}+40 \%$ de CAC $+15 \%$ de $\mathrm{FC}+5 \%$ de $\mathrm{CO}+0 \%$ de SC.

Médias, nas colunas, seguidas de asterisco $\left({ }^{*}\right)$, diferem da testemunha ao nível de $5 \%$ de probabilidade, pelo Teste Dunnet ${ }^{1}$. Significativo para o Teste $F$, porém, sem diferenças $(p>0,05)$ quando comparados, o controle, e cada um dos níveis de moinha.

Nas Figuras 2a, 2b e 2c apresentam-se a MSPA, MSR e o DC, respectivamente, em função de porcentagens crescentes de moinha na composição dos substratos. De acordo com a análise de regressão, verifica-se que a variável MSR manifestou comportamento linear, já as variáveis MSPA e DC apresentaram um comportamento polinomial quadrático, em função das diferentes porcentagens de moinha na composição dos substratos para as mudas de pepino.

Analisando-se a Tabela 3, observa-se que para a variável MSPA, os substratos alternativos não diferem da testemunha (uso exclusivo do substrato comercial) $(p>0,05)$, obtendo-se valores que variam de $48,33 \mathrm{mg}$ (T6) a $67,50 \mathrm{mg}$ (T4). Tais resultados indicam que, para esta variável, é possível utilizar proporções de até $40 \%$ de moinha, possibilitando a substituição total do substrato comercial $(0 \%)$. No entanto, dentre as proporções analisadas, a porcentagem estimada de $15,45 \%$ de moinha na composição do substrato proporcionou os maiores resultados $(64,19 \mathrm{mg}$ ) para MSPA (Figura 2a). Os menores valores de MSPA foram obtidos nos substratos contendo as menores proporções de moinha (abaixo de 15,45\%) e nas maiores (acima de 15,45\%). No primeiro caso, tal fato possa estar associado à menor quantidade de nutrientes, em razão da ausência da moinha. Já no segundo, a elevada salinidade, evidenciada pela condutividade elétrica nos substratos contendo as maiores proporções de moinha (Figura 1a), possa ter prejudicado a quantidade de MSPA.

De acordo com OLIVEIRA et al. (2015), a redução do acúmulo de fitomassa na parte aérea em função do aumento da salinidade indica ineficiência do processo fotossintético, de modo que os produtos oriundos da fotossíntese não são suficientes para suprir as necessidades dos órgãos das plantas, e ao mesmo tempo promover o crescimento destes.

Segundo COSTA et al. (2013), pela massa de matéria seca é possível saber qual substrato forneceu maior quantidade de nutrientes para as mudas. Nesse sentido, o substrato contendo em torno de $15 \%$ forneceu a adequada quantidade de nutrientes sem que a salinidade influenciasse negativamente na quantidade de MSPA.

Para a variável MSR (Tabela 3), apenas o substrato contendo $40 \%$ de moinha $+40 \%$ casca de arroz carbonizada $+15 \%$ de fibra de coco $+0 \%$ de substrato comercial (T6) difere da testemunha (uso exclusivo de substrato comercial). Os demais tratamentos com substratos alternativos não diferem da testemunha ao nível de $5 \%$ de probabilidade. Tal resultado indica que para esta variável é possível utilizar doses de até $30 \%$ de moinha, sem causar prejuízos às mudas de pepino, ainda que se verifique diminuição da matéria seca de raiz com o acréscimo de moinha no substrato (Figura $2 b$ ). 
(a)

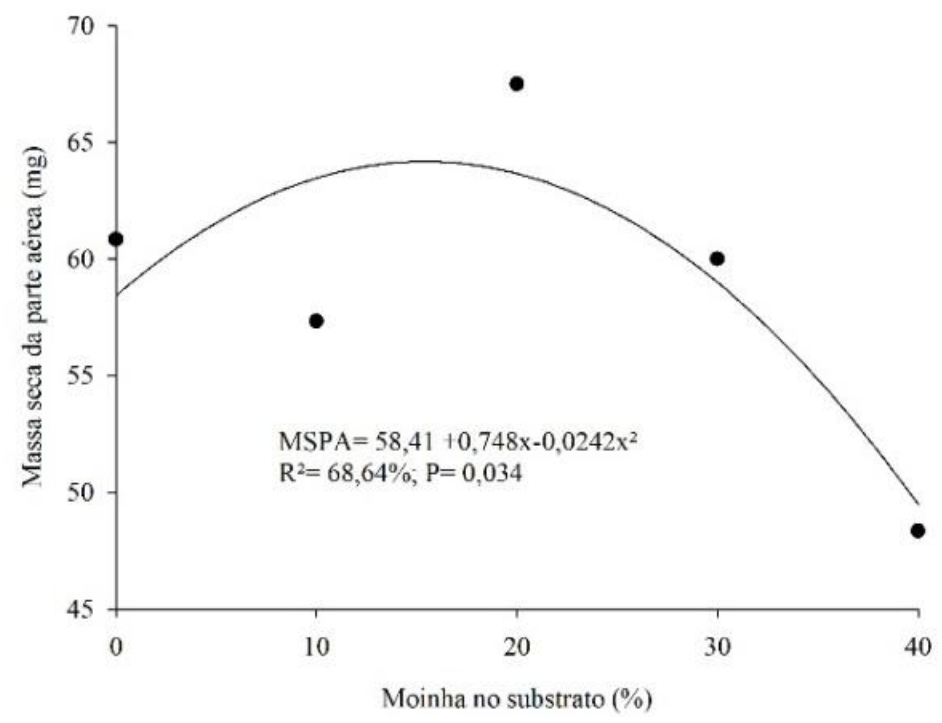

(b)

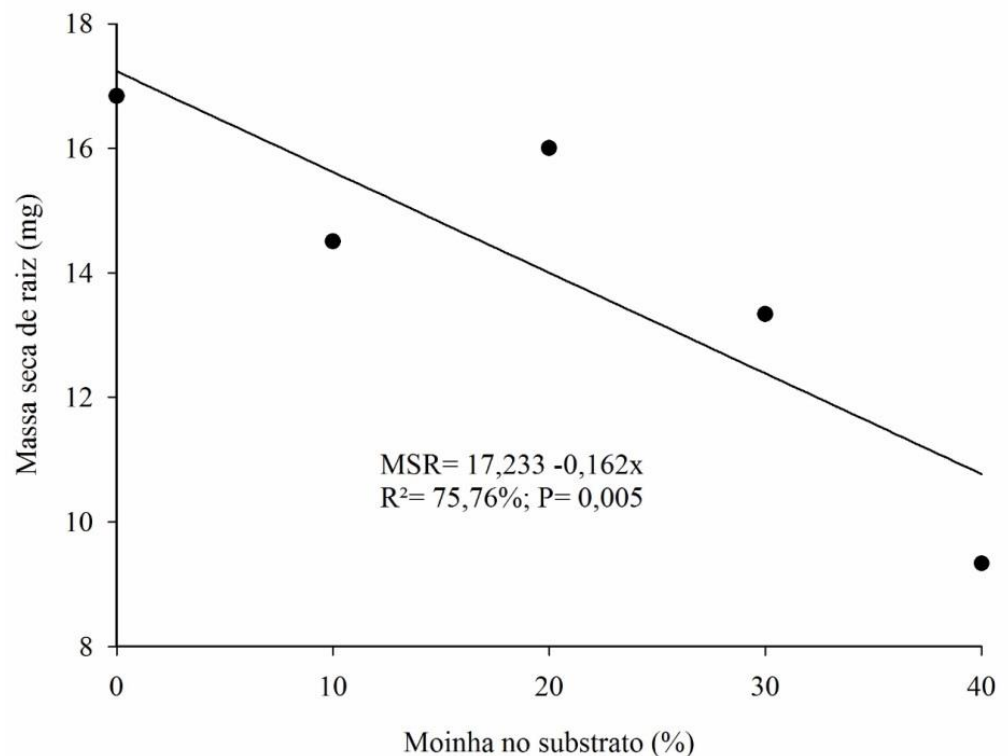

(c)

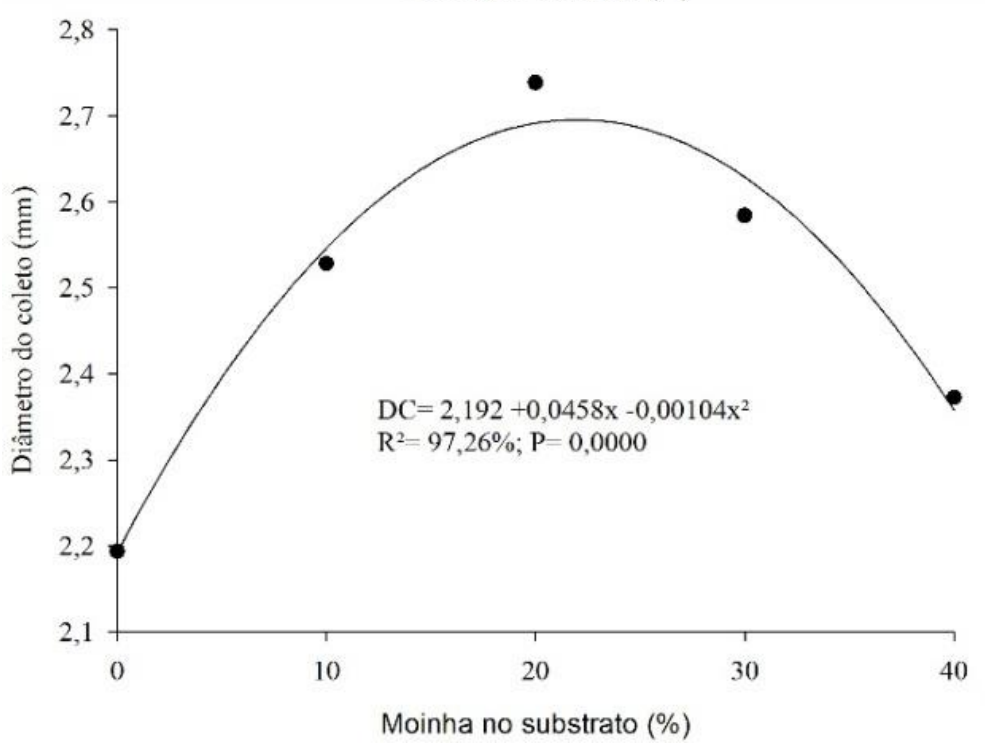

Figura 2. Massa seca da parte aérea (a), massa seca de raíz (b) e diâmetro de caule (c) de mudas de pepino, em função dos substratos com os diferentes níveis de moinha. IFES, Campus Santa Teresa, 2017.

Figure 2. Dry mass of the aerial part (a), root dry mass (b) and stem diameter (c), of cucumber seedlings, in regarding the substrates with different levels of chaff. IFES, Campus Santa Teresa, 2017. 
De acordo com MAROUELLI et al. (2005), o acúmulo de biomassa radicular está condicionado ao limite físico da célula da bandeja devido à disponibilidade de água e nutrientes, aeração do substrato e níveis de salinidade. Nesse sentido, acredita-se que, tal como observado para a variável MSPA (Figura 2a), o aumento da salinidade no substrato com o acréscimo da moinha possa ter sido um dos motivos pelo decréscimo nos valores de MSR. ALBUQUERQUE et al. (2016), ao analisarem o crescimento inicial e a tolerância de cultivares de pepino sob estresse salino, verificaram drásticas reduções no acúmulo de massa seca das raízes em função do aumento da salinidade. Os autores constataram valores de até $0,011 \mathrm{~g}$ de MSR em mudas de pepino quando irrigadas ao nível máximo de salinidade $\left(3 \mathrm{dS} \mathrm{m}^{-1}\right)$. Enquanto para a menor concentração de salinidade $\left(0,6 \mathrm{dS} \mathrm{m}^{-1}\right)$, os autores obtiveram $0,031 \mathrm{~g}$ para MSR.

Os resultados obtidos para a MSR neste trabalho apresentam-se satisfatórios quando comparados com LIMA et al. (2007), que ao estudarem resíduos da agroindústria de chá preto como substrato para produção de mudas de pepino, obtiveram, aos 15 DAS, um valor de 2,49 mg de MSR, utilizando resíduo de composto + vermiculita.

De acordo com SANTOS et al. (2010), o maior diâmetro de caule pode ser demonstrativo de plantas mais vigorosas. Nesse sentido, observa-se que todos os tratamentos contendo substratos alternativos foram estatisticamente superiores ao tratamento testemunha (uso exclusivo do substrato comercial) ao nível de $5 \%$ de probabilidade (Tabela 3), indicando que para esta variável, é possível utilizar doses de até $40 \%$ de moinha, sem prejudicar as mudas de pepino, e ainda obter resultados excedentes à testemunha. No entanto, entre as proporções estudadas, a proporção estimada de $22,02 \%$ de moinha na composição do substrato alternativo apresentou o melhor resultado $(2,70 \mathrm{~mm})$ para diâmetro do caule (Figura $2 \mathrm{c}$ ). Os menores valores foram obtidos nas menores proporções de moinha (abaixo de $22,02 \%$ ) e nas maiores (acima de 22,02\%). No primeiro caso, a menor quantidade de nutrientes presentes no substrato, em razão da ausência da moinha, possa ter sido o motivo pelo qual obteve-se menor diâmetro de caule. No segundo caso, as maiores concentrações de moinha acarretaram numa maior salinidade do substrato (Figura 1), prejudicando no crescimento do diâmetro de caule.

Os resultados obtidos neste trabalho encontram-se semelhantes aos encontrados por LEITE et al. (2014), que ao estudarem a influência de substratos e recipientes no desenvolvimento de mudas de pepino, não encontraram valores superiores a $2,6 \mathrm{~mm}$ para o diâmetro de caule das mudas no tratamento com húmus e casca de arroz carbonizada.

A variável altura de planta (AP) não foi significativa ao nível de $5 \%$ de probabilidade (Tabela 3 ), obtendo-se valores médios variando de $7,60 \mathrm{~cm}$ (T6) até $9,72 \mathrm{~cm}$ (T4), nos tratamentos contendo proporções crescentes de moinha. Tais resultados indicam que, para esta variável, é possível utilizar proporções de até $40 \%$ de moinha, possibilitando a substituição total do substrato comercial $(0 \%)$. Os resultados obtidos neste trabalho mostram-se superiores quando comparados com outros trabalhos utilizando resíduos orgânicos em substratos para produção de mudas de pepino. CERQUEIRA et al. (2015), avaliando substratos (combinação de húmus + casca de arroz carbonizada) e recipientes no desenvolvimento de mudas de pepino, não encontraram valores superiores a $3,5 \mathrm{~cm}$ para a altura de mudas, porém, avaliando-se aos 19 DAS.

A variável número de folhas (Tabela 3) também não foi significativa ao nível de $5 \%$ de probabilidade, obtendo-se valores médios variando de 3,05 (T6) até 3,13 unidades de folha (T3), nos tratamentos contendo proporções crescentes de moinha. Nesse caso, é possível utilizar proporções de até $40 \%$ de moinha (substituição total do substrato comercial) na composição do substrato, sem que haja prejuízo no número de folhas. Os resultados obtidos neste trabalho apresentam-se satisfatórios quando comparados com SILVA et al. (2014), que ao avaliarem a qualidade de mudas de pepino cv. Caipira produzidas com substratos à base de esterco ovino, obtiveram, aos 43 DAS, número de folhas variando de 1,63 a 1,98 unidades.

Os resultados satisfatórios obtidos neste trabalho para esta variável possam estar relacionados à liberação de nutrientes do material orgânico presente no substrato, ao longo dos 21 dias em que as plantas permaneceram nas bandejas sob boas condições de umidade. LARCHER (2000) ressalta que os elementos minerais, componentes dos substratos, são utilizados como ativadores diretos do processo fotossintético, ocorrendo, quase sempre, maiores taxas fotossintéticas em plantas bem nutridas, melhorando 0 desenvolvimento das mesmas.

\section{CONCLUSÃO}

Proporções crescentes de moinha acarretam no aumento da condutividade elétrica no substrato. Proporções em torno de 15 a $20 \%$ de moinha na composição do substrato apresentam os maiores valores de matéria seca da parte aérea, de raiz e diâmetro do caule. Proporções de até $30 \%$ de moinha em 
substrato composto por $40 \%$ de casca de arroz, $15 \%$ de fibra de coco, $5 \%$ de casca de arroz e $10 \%$ de substrato comercial também podem ser utilizadas sem que haja prejuízo nas variáveis de crescimento em mudas de pepino.

\section{AGRADECIMENTOS}

A segunda autora agradece à Fundação de Amparo à Pesquisa e Inovação do Espírito Santo (FAPES), pela bolsa concedida de Pesquisadora Capixaba.

\section{REFERÊNCIAS}

ALBUQUERQUE JRT et al. 2016. Crescimento inicial e tolerância de cultivares de pepino sob estresse salino. Revista Brasileira de Agricultura Irrigada 10: 486-495.

ARAÚJO NETO SE et al. 2009. Produção de muda orgânica de pimentão com diferentes substratos. Ciência Rural 39: 1408-1413.

CAVINS TJ et al. 2000. Monitoring and managing pH and EC using the Pour Thru Extraction Method. Orticulture Information Leaflet 590: 1-17.

CARRIJO OA et al. 2002. Fibra da casca do coco verde como substrato agrícola. Horticultura Brasileira 20: 533-535.

CASTOLDI G et al. 2014. Substratos alternativos na produção de mudas de alface e sua produtividade no campo. Revista Ciência Agronômica 45: 299-304.

CERQUEIRA FB et al. 2015. Substratos e recipientes no desenvolvimento de mudas de pepino em alta temperatura. Global Science And Technology 8: 61-73.

COSTA LAM et al. 2013. Avaliação de substratos para a produção de mudas de tomate e pepino. Revista Ceres 60 : 675-682.

GRAVINA GA et al. 2004. Transformação de dados nas estimativas de parâmetros genéticos de resistência dos cultivares de soja Uberaba e Bossier à Cercospora sojina Hara. Revista Ceres 51: 215-225.

LARCHER W. 2000. Ecofisiologia vegetal. 1.ed. São Carlos: RIMA. 531p.

LEITE RC et al. 2014. Influência de substratos e recipientes no desenvolvimento de mudas de pepino. In: Amazon Soil - I Encontro de Ciência do Solo da Amazônia Oriental, Sociedade Brasileira de Ciência do Solo, Núcleo Regional Amazônia Oriental, Anais... Trabalhos completos, Gurupi: SBCS. p. 140-150.

LIMA JD et al. 2007. Resíduos da agroindústria de chá preto como substrato para produção de mudas de hortaliças. Ciência Rural 37: 1609-1613.

MAROUELLI WA et al. 2005. Variabilidade espacial do sistema radicular do tomateiro e implicações no manejo da irrigação em cultivo sem solo com substratos. Horticultura Brasileira 23: 57-60.

MATOS AT. 2015. Manual de análise de resíduos sólidos e águas residuárias. 1.ed, Viçosa: UFV. 149p.

MEDEIROS FM \& ALVES MGM. 2014. Qualidade de ovos comerciais. Revista Eletrônica Nutritime 11: 3515-3524.

MENEGHELLI CM et al. 2016. Resíduo da secagem dos grãos de café como substrato alternativo em mudas de café Conilon. Coffee Science 11: 329-334.

OLIVEIRA FA et al. 2015. Emergência e crescimento inicial de plântulas de beterraba cv. Chata do Egito sob estresse salino. Agropecuária Científica no Semiárido 11: 1-6.

PAIXÃO MVS et al. 2012. Frações orgânicas e mineral na produção de mudas de mamoeiro. Revista Brasileira de Fruticultura 34: 1105-1112.

RIBEIRO MCC et al. 2001. Efeito da salinidade na germinação de sementes de quatro cultivares de girassol (Helianthus annuus L.). Revista Brasileira de Sementes 23: 281-284.

SANTOS MR et al. 2010. Produção de mudas de pimentão em substratos à base de vermicomposto. Bioscience Journal 26: $572-578$.

SILVA LJB et al. 2009. Produção de mudas de rúcula em bandejas com substratos a base de resíduos orgânicos. Ciência e Agrotecnologia 33: 1301-1306.

SILVA EF et al. 2014. Qualidade de mudas de pepino produzidas em substratos à base de esterco ovino. Agropecuária Científica no Semiárido 10: 93-99.

UFV. 2007. Universidade Federal de Viçosa. SAEG - Sistema para análises estatísticas. Versão 9.1. Viçosa: Fundação Arthur Bernardes (CD-ROM). 